University of Nebraska - Lincoln

DigitalCommons@University of Nebraska - Lincoln

$4-2020$

\title{
Distortion of the Local Magnetic Field Appears to Neither Disrupt Nocturnal Navigation nor Cue Shelter Recognition in the Amblypygid Paraphrynus laevifrons
}

Daniel D. Wiegmann

Patrick Casto

Eileen Hebets

Verner P. Bingman

Follow this and additional works at: https://digitalcommons.unl.edu/bioscihebets

Part of the Animal Sciences Commons, Behavior and Ethology Commons, Biology Commons, Entomology Commons, and the Genetics and Genomics Commons

This Article is brought to you for free and open access by the Papers in the Biological Sciences at DigitalCommons@University of Nebraska - Lincoln. It has been accepted for inclusion in Eileen Hebets Publications by an authorized administrator of DigitalCommons@University of Nebraska - Lincoln. 


\title{
Distortion of the Local Magnetic Field Appears to Neither Disrupt Nocturnal Navigation nor Cue Shelter Recognition in the Amblypygid Paraphrynus laevifrons
}

\author{
Daniel D. Wiegmann, ${ }^{1,2}$ Patrick Casto, ${ }^{1}$ Eileen A. Hebets, ${ }^{3}$ \\ and Verner P. Bingman 2,4
}

1. Department of Biological Sciences, Bowling Green State University, Bowling Green, Ohio, USA

2. J. P. Scott Center for Neuroscience, Mind and Behavior, Bowling Green State University, Bowling Green, Ohio, USA

3. School of Biological Sciences, University of Nebraska-Lincoln, Lincoln, Nebraska, USA

4. Department of Psychology, Bowling Green State University, Bowling Green, Ohio, USA

Corresponding author - Daniel D. Wiegmann, Department of Biological Sciences, Bowling Green State University, Bowling Green, OH, 43403, email ddwiegm@bgsu.edu. ORCID https://orcid.org/0000-0001-7259-3157

\begin{abstract}
Many arthropods are known to be sensitive to the geomagnetic field and exploit the field to solve spatial problems. The polarity of the geomagnetic field is used, for instance, as an orientation cue by leafcutter ants as they travel on engineered trails in a rainforest and by Drosophila larvae as they move short distances in search of food. A ubiquitous orientation cue like the geomagnetic field may be especially useful in complex, cluttered environments like rainforests, where the reliability of celestial cues used to navigate in more open environments may be poor. The neotropical amblypygid Paraphrynus laevifrons is a nocturnal arachnid that wanders nightly in the vicinity of its shelter and occasionally travels $30 \mathrm{~m}$ or more in the rainforest understory before it returns to its shelter. Here, we conducted a field experiment to determine whether navigation by $P$. laevifrons is guided by the ambient magnetic field and a complementary laboratory experiment to assess whether a magnetic anomaly could be used to pinpoint the entrance of a shelter. In the field experiment, subjects were fitted with a radio transmitter and a small, powerful magnet or a similar-sized brass disk and displaced
\end{abstract}


$10 \mathrm{~m}$ from their shelter. The return rate of magnet-fitted subjects was similar to that of brass-fitted subjects and to that of subjects in an earlier study fitted with only a radio transmitter. In the laboratory experiment, we trained $P$. laevifrons with a protocol under which the amblypygid Phrynus marginemaculatus rapidly learns - in 1-14 trials over two daily sessions - to associate an olfactory stimulus with access to a shelter. The conditioned stimulus here was a magnetic anomaly characterized by a high total field intensity and a $180^{\circ}$ reversal of the polarity of the ambient magnetic field. The magnetic anomaly-shelter contingency was not learned in 50 trials conducted over 10 daily sessions. These results imply prima facie that $P$. laevifrons does not rely on a magnetic compass to locate or recognize a shelter and, perhaps, that the magnetic field cannot be detected, but alternative explanations are discussed.

Keywords: amblypygid, geomagnetic field, navigation, whip spider

\section{Introduction}

Diurnal terrestrial arthropods that inhabit largely open, two-dimensional habitats, like the desert ant Cataglyphis fortis or the fiddler crab Uca rapax, as a rule use path integration to navigate to a nest or shelter (Cheng, 2012; Collett \& Collett, 2017; Heinz, Narendra, \& Cheung, 2018; Perry, Barron, \& Cheng, 2013). Typically, a sun compass and optical flow or idiothetic cues provide directional and distance information that is used to compute a homeward vector (Layne, Barnes, \& Duncan, 2003a, 2003b; Mittelstaedt \& Mittelstaedt, 1982; Reyes-Alcubilla, Ruiz, \& Ortega-Escobar, 2009; Wehner, 2003). Even nocturnal arthropods, like the desert spider Leucorchestris arenicola and the wolf spider Lycosa tarantula, seem to require visual cues to navigate (Ortega-Escobar, 2002; Ortega-Escobar \& Ruiz, 2014, 2017; Nørgaard, Nilsson, Henschel, Garm, \& Wehner, 2008; Nørgaard, Gagnon, \& Warrant, 2012; reviewed by Warrant \& Dacke, 2010).

In complex habitats, like the floor of a rainforest, directional information derived via a path integration mechanism or from nocturnal celestial cues is probably less reliable and these habitats may consequently demand navigation strategies that are more flexible with regard to sensory control, strategies that incorporate sequential or integrated inputs from multiple sensory modalities (Wiegmann, Hebets, Gronenberg, Graving, \& Bingman, 2016; see also Heinze et al., 2018). Experiments with arthropods that inhabit simple environments reveal that even they routinely utilize multiple sensory modalities to locate a goal. The desert ant $C$. fortis, for instance, uses path integration at long distances from its nest and at close distances exploits odors to pinpoint the nest entrance (Steck, Hansson, \& Knaden, 2009, 2011). Recent evidence suggests that Cataglyphis could, at least in principle, also use magnetic or vibrational landmarks to identify the location of a nest entrance at the end of an inbound journey (Buehlmann et al., 2012). In complex environments, stable and ubiquitous cues, like the magnetic field, might be particularly useful (Wajnberg et al., 2010). Leaf cutter ants, for instance, use the magnetic field as a reference for path integration as they travel on engineered trails (Riveros \& Srygley, 2008). Even Drosophila larvae, which travel extraordinarily short distances, use the ambient magnetic field as a reference for orientation (Dommer, Gazzolo, Painter, \& Phillips, 2008). Indeed, insects are able to use the magnetic field to solve a variety of spatial problems (Cardé, 2008; Chapman et al., 2008; 
Chittka, Williams, Rasmussen, \& Thomson, 1999; Frier, Edwards, Smith, Neale, \& Collet, 1996; Srygley, Dudley, Oliveira, \& Riveros, 2006; Walker, 1997).

Nocturnal arachnids in the Order Amblypygi, known as whip spiders, inhabit the tropics and subtropics, where they reside in the same shelter for weeks or months (Beck \& Görke, 1974; Hebets, 2002; Segovia, Neco, \& Willemart, 2018; Weygoldt, 2000). Individuals make short nightly excursions in the vicinity of their shelter and occasionally wander longer distances $-30 \mathrm{~m}$ or more-presumably in search of prey or a mate and return several nights later (Hebets, 2002). Displacement experiments revealed that amblypygids do not rely on path integration to locate their shelter (Hebets, Gering, Bingman, \& Wiegmann, 2014). Navigation appears instead to be guided by specialized sensory structures called antenniform legs (Bingman, Graving, Hebets, \& Wiegmann, 2017; Hebets, Aceves-Aparicio, et al., 2014; Hebets, Gering, et al., 2014). These appendages are highly articulated, covered with mechanosensory, chemosensory, and olfactory sensilla and serve no locomotor function (Beck, Foelix, Gödeke, \& Kaiser, 1977; Foelix, 1975; Foelix \& Hebets, 2001; Santer \& Hebets, 2011; Weygold, 2000). In the laboratory, amblypygids can be conditioned to tactile or olfactory cues that identify the location of an accessible shelter (Santer \& Hebets, 2009; Wiegmann et al., 2019; see also Casto, Gosser, Wiegmann, Hebets, \& Bingman, 2019). Indeed, navigation in the field appears to depend strongly on olfactory and perhaps other sensory inputs detected by receptors on the antenniform legs (Bingman et al., 2017; Hebets, Aceves-Aparicio, et al., 2014). Putative multisensory navigational control is implicated by the enormity of their mushroom bodies - higher-order brain structures that, in insects, process olfactory information and are involved in sensory integration - which are proportionally larger than those of any other studied arthropod (Strausfeld, 2012; see Wiegmann et al., 2016). However, the suite of sensory stimuli that contributes to amblypygid navigation behavior has yet to be fully explored.

In this study, we conducted two experiments, one in the field and one in the laboratory, to determine whether the neotropical amblypygid Paraphrynus laevifrons relies on the geomagnetic field to navigate to a shelter and whether, like Cataglyphis, amblypygids are able to use a magnetic anomaly to pinpoint the location of a shelter. The experiments involved the use of magnets, which disrupted both the polarity and intensity of the local magnetic field, and we hypothesized that the magnets would impede navigation and reliably cue shelter recognition if amblypygids employ a magnetic compass that involves any combination of components of the magnetic field.

\section{Materials and Methods}

\subsection{Field study}

This study was conducted at La Suerte Biological Field Station, Limon, Costa Rica $\left(83^{\circ} 46^{\prime} 1^{\prime \prime} \mathrm{W}, 10^{\circ} 26^{\prime} 30^{\prime \prime} \mathrm{N}\right)$ on May. 25-31, 2016. Telemetry was used to track the movements of Paraphrynus laevifrons after displacements of $10 \mathrm{~m}$, as in our earlier displacement experiments (Bingman et al., 2017). 


\subsubsection{Subjects}

Twelve Paraphrynus laevifrons were captured from trees at night after they emerged from their tree crevice refuges. Each subject was fitted with an Advanced Telemetry Systems A2414 transmitter (144.06-151.98 MHz) and either a small solenoid neodymium magnet (K \& J Magnetics Inc., D21: $3.18 \mathrm{~mm}$ diameter, $1.59 \mathrm{~mm}$ height, surface field 4,667 Gauss; $N=8$ ) or a similar-sized disk made of brass $(N=4$; Figure 1$)$. The field generated by the magnet drops to zero at a distance of 60-75 mm (https://www.kjmagnetics.com/fieldcalcu lator.asp). Fewer subjects were included in the control group because transmitters were limited and return rates for similarly displaced subjects were known from earlier experiments (Bingman et al., 2017). The radio transmitter and magnet or brass disk were affixed with a cyanoacrylate adhesive to the posterior, dorsal prosoma (cephalothorax) of each individual.
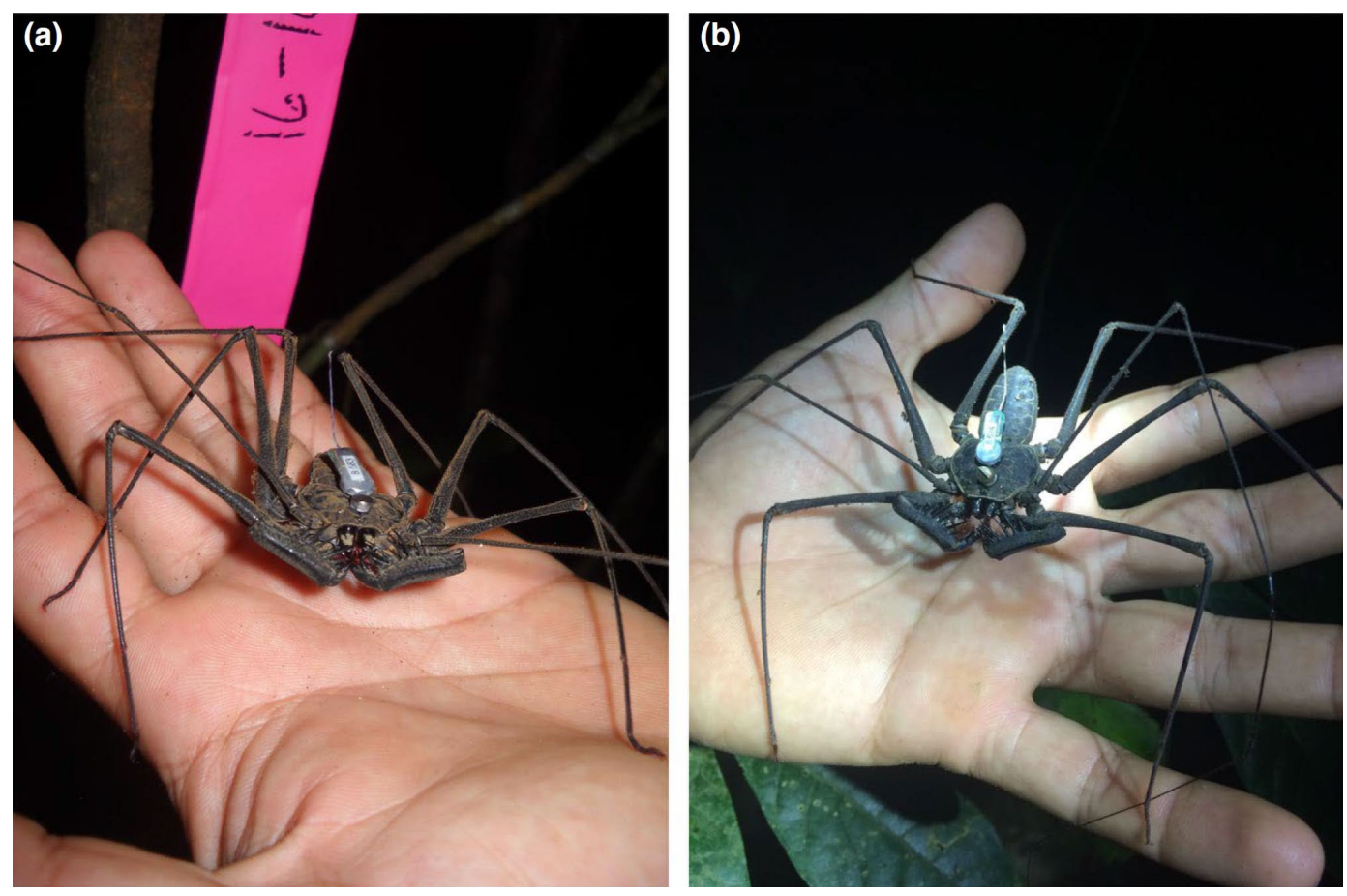

Figure 1. Photograph of Paraphrynus laevifrons fitted with a radio transmitter and a (a) magnet or (b) brass disk.

\subsubsection{Procedures}

Subjects were captured from their resident trees by hand. Individuals were sexed and their prosoma width was measured to the nearest $\mathrm{mm}$. Each subject was then assigned pseudorandomly to the treatment (magnet, $\mathrm{M}+$ ) or control (brass disk, $\mathrm{M}-$ ) group-where four subjects were predetermined to be included in the latter group-and a radio transmitter and magnet or bass disk were affixed. After the adhesive dried, 2-5 min later, a subject was displaced $10 \mathrm{~m}$ in a haphazard direction from the tree on which it was captured and 
placed on the ground. Flagging tape was used to mark displacement locations. All displacements occurred between 19:00 and 23:00 hr.

Every subject was located daily with an Advanced Telemetry Systems R410 receiver. The distance and direction of the current location of a subject to its last known position were recorded. The location to which a subject was displaced with respect to its resident tree was also recorded. Positional information was collected in daylight hours between 08:30 and 13:00 hr so as not to interfere with any nocturnal movements.

\subsubsection{Statistics}

A $V$ test was used to assess whether the distribution of bearings between the release site and the observed locations of subjects the day after they were displaced differed from uniform, with the direction to the tree from which a subject was collected as the predicted direction of movement (Batschelet, 1981). An analogous test was conducted for subjects that had not homed by May 15, 2016, the last day that data were collected. A Fisher exact test was used to compare the proportion of individuals in the two groups that successfully homed (Sokal \& Rohlf, 2012). The return rate of M+ subjects was also compared to the rate of return for subjects in an earlier study that was fitted with only a radio transmitter and likewise displaced $10 \mathrm{~m}$ (Bingman et al., 2017). A Watson $U^{2}$ test was used to determine whether the direction of displacement differed between subjects in the M+ and M- groups, between subjects that did or did not home successfully and to compare the orientation of subjects in the M+ and M- groups that had not homed by May 15, 2016 (Mardia \& Jupp, 2000). For all tests, we used a significance level of $\alpha=.05$.

\subsection{Shelter recognition laboratory experiment}

A laboratory experiment was conducted to assess whether, under controlled conditions, $P$. laevifrons could be trained to associate a localized magnetic anomaly, characterized by a high field intensity and a $180^{\circ}$ reversal of polarity of the ambient magnetic field, with access to a shelter. The procedures we used were adapted from methods that Buehlmann, Hansson, and Knaden (2012) employed to train the desert ant Cataglyphis noda to associate a magnetic landmark with a nest entrance and methods that Wiegmann et al. (2019) used to train the amblypygid Phrynus marginemaculatus to associate an odor with the entrance to a shelter.

\subsubsection{Subjects}

The experiment involved six adult $P$. laevifrons collected at the La Suerte Biological Field Station in May 2016 (permit 144-17-ACLA-P). Subjects were housed individually in a medium $(23 \mathrm{~cm} \times 15 \mathrm{~cm} \times 15 \mathrm{~cm})$ or large $(30 \mathrm{~cm} \times 19 \mathrm{~cm} \times 20 \mathrm{~cm})$ Kritter Keeper ${ }^{\circledR}$ that had a coconut fiber substrate and contained a piece of cork bark for shelter. The insides of the containers were sprayed daily with reverse osmosis water, and we fed subjects crickets two to three times weekly. The room in which subjects were housed, also used for the experiment, was lit by overhead broad-spectrum fluorescent lights $(400-750 \mathrm{~nm})$ set on a 12:12 hr light:dark cycle (19:00-07:00 dark phase). The humidity of the room was $25 \%-55 \%$ and the air temperature was $23-28^{\circ} \mathrm{C}$. 


\subsubsection{Procedures}

Each subject was trained and tested in 10 daily sessions that started and ended with a test trial, separated by five trials in which the subject was conditioned to associate a magnetic anomaly with access to a shelter. The experiment was conducted in a dedicated location in our laboratory in a rectangular arena constructed from opaque white acrylic plastic, the floor of which was demarcated into three similar-sized sections (Figure 2). The arena had a $3 \mathrm{~cm} \times 1 \mathrm{~cm}(\mathrm{~L} \times \mathrm{H})$ hole centered at floor level on each short wall, which served as a possible entrance to a shelter, and an identical hole in the middle of a long wall, equidistant to the two shelter entrances, where a subject was released. The shelters were constructed of black acrylic. Two 60-watt equivalent spiral CFL light bulbs-900 lumens each-mounted above the short walls were used to motivate subjects to seek refuge in a shelter. The lights were oriented on the long axis of the arena and pointed downward toward the center of the arena at an angle of about $45^{\circ}$ so that the top of each bulb was approximately $15 \mathrm{~cm}$ from the arena floor.

A Silva ${ }^{\circledR}$ Polaris 177 baseplate compass was used to align the arena lengthwise on the west-east axis of the ambient magnetic field. Two neodymium solenoid magnets (K \& J Magnetics Inc., D36-N52: $4.8 \mathrm{~mm}$ diameter, $9.5 \mathrm{~mm}$ length, surface field 7,179 Gauss) that were mounted on the surface of $2.5 \mathrm{~cm} \times 2.5 \mathrm{~cm} \times 1 \mathrm{~cm}$ pieces of plastic acrylic were placed in series outside the arena near one of the shelter entrances, designated $\mathrm{M}+$. The compass was used to align the magnets to produce a $180^{\circ}$ reversal of the polarity of the ambient magnetic field $2.5 \mathrm{~cm}$ from the entrance to $\mathrm{M}+$ (Figure 2). Two brass disks similar in size to the magnets that were likewise mounted on acrylic cubes - and caused no perturbation to the ambient magnetic field-were placed in analogous locations near the other shelter, designated $\mathrm{M}$-. The $x$ (north positive), $y$ (east positive), and $z$ (vertical, downward positive) field component strengths in the arena were not experimentally controlled, but the component intensities were measured at five positions between $\mathrm{M}-$ and $\mathrm{M}+$ with an iPhone 8 (Sensor Kinetics 2.1.1, Innoventions Inc.) on 10 days, after placement of the magnets and brass disks, to ensure consistency of the magnetic field. The magnets induced a large shift of the $x$ field component intensity, which induced the observed rotation of the horizontal component of the field but had little influence on $y$ or $z$, with no impact on the sign of $z$ (Figure 2). Hence, the shelters might be discriminated by a polarity compass or an inclination compass and discrimination under our magnetic field manipulation can provide no evidence about which type of compass is used (see Vácha, Drštková, \& Půžová, T., 2008; Wajnberg et al., 2010). The component intensities of the ambient magnetic field, which correspond to those at position 1 in Figure 2, differed somewhat from expected based on our geographical location due ostensibly to magnetic material in the vicinity of our laboratory (https://www.ngdc.noaa.gov/geomag/calculators/magcalc.shtml\#igrfwmm). 


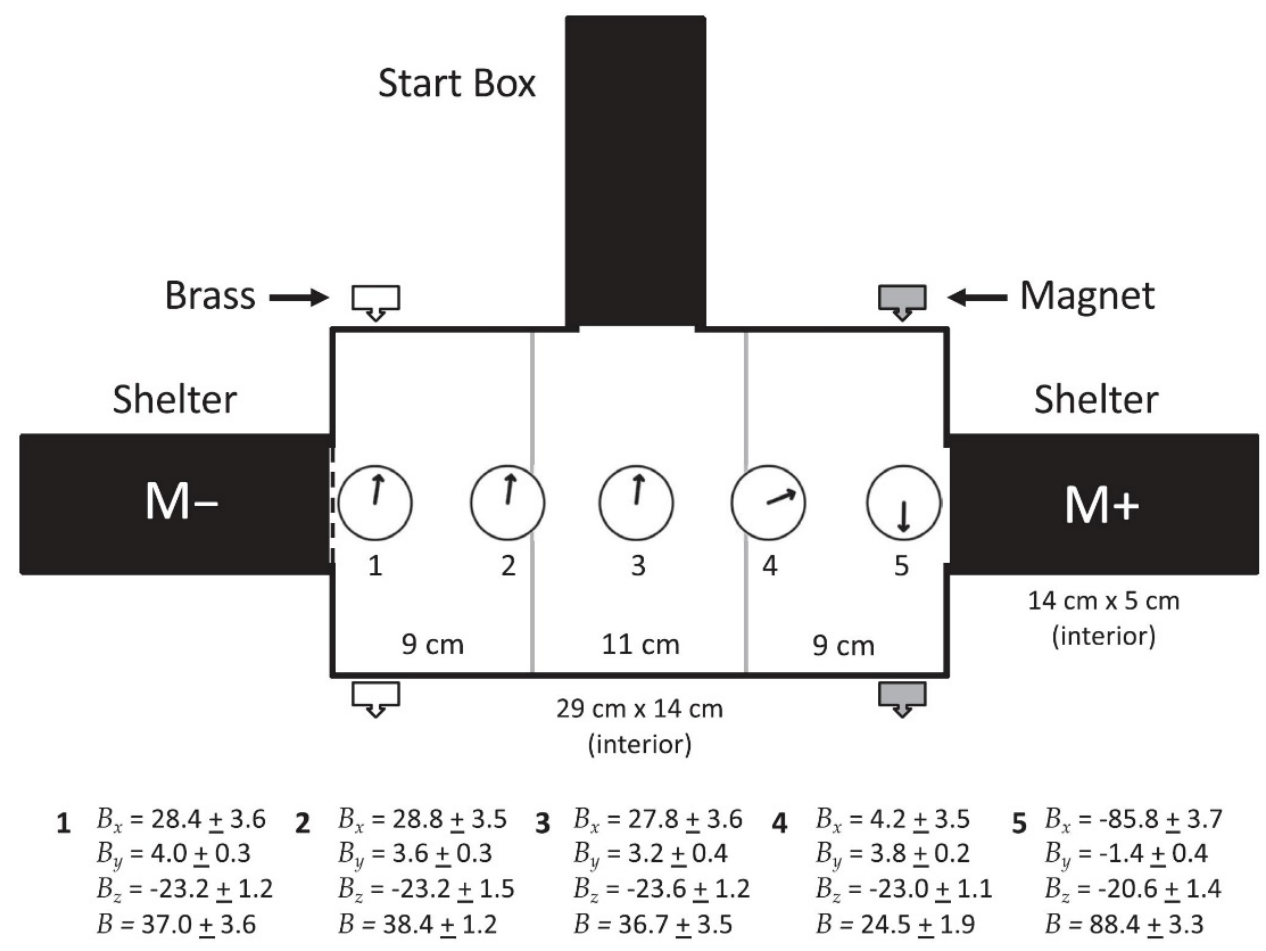

Figure 2. Experimental arena. Two solenoid magnets were positioned outside the arena to alter the polarity of the ambient magnetic field by $180^{\circ}$ near the entrance to one of the shelters, M+. Two similar-sized brass disks were mounted near the other shelter, $\mathrm{M}-$. The arrangement depicts a training trial for a subject conditioned to associate the magnetic landmark anomaly with access to a shelter. The entrance to M+ is open, and a plastic screen (dashed line) blocks the entrance to $\mathrm{M}-$. In tests, both entrances were blocked and the time a subject spent in the region near each shelter (demarcated by vertical gray lines) was used to compute an association index, $\theta$. The mean ( $\pm 1 \mathrm{SE})$ intensities $B_{x}, B_{y}$, and $B z$ $(\mu \mathrm{T})$ of the orthogonal $x, y$, and $z$ components of the magnetic field and the total magnetic field intensity $B$ measured at five positions labeled 1-5 are indicated. The intensities were measured after a compass was used to position the magnets, with brass disks placed in analogous locations near $\mathrm{M}-$. The mean magnetic field horizonal polarity, computed from the paired $x$ and $y$ component intensities, is shown at positions $1-5$ by arrows inside open circles.

When the arena had been prepared, a subject was placed into a black acrylic start box that was open at one end and had a removable lid. A piece of black acrylic plastic covered the open end, which was positioned in front of the hole in the long wall of the arena, and was removed with the box lid after a 5-min acclimation period. The subject was then coaxed with a blunt dissection probe into the arena, and the start box entrance was again blocked with the piece of black acrylic plastic. If a subject was trained to associate access to a shelter with the magnetic anomaly, then the entrance to $\mathrm{M}+$ was open and the entrance to $\mathrm{M}$ - was blocked by a plastic screen, and vice versa. 
A subject was given $10 \mathrm{~min}$ to discover and enter the accessible shelter. If a subject failed to enter the open shelter in $10 \mathrm{~min}$, a blunt dissection probe was used to gently coax it into the shelter. The open end of the shelter was then covered with a piece of black acrylic plastic, and the shelter was repositioned to the location of the start box, where the subject was left undisturbed for $5 \mathrm{~min}$. Meanwhile, an equivalent shelter was placed in the location of the shelter that was moved and right-left positions for $\mathrm{M}+$ and $\mathrm{M}$ - were determined. The west-east orientation of the arena was then adjusted, if necessary, and magnets and brass disks were appropriately positioned. After the 5-min rest period, the subject was again released into the arena. This process was repeated over the sequence of five training trials in a session on a particular day, where the right-left positions of $\mathrm{M}+$ and $\mathrm{M}$ - were randomly determined. Three of the subjects were trained to $\mathrm{M}+$, and three were trained to $\mathrm{M}-$.

Test trials were conducted similarly except that the arena floor and walls were cleaned with ethanol and the entrance to each shelter was blocked. The time a subject occupied the demarcated area of the arena near each shelter entrance was recorded with a stopwatch for $15 \mathrm{~min}$ after the subject was released, where a subject was deemed to occupy a particular region of the arena if more than half of its prosoma was within a delineated area. The right-left positions of $\mathrm{M}+$ and $\mathrm{M}$ - in all tests were determined randomly.

\subsubsection{Statistics}

The time a subject occupied the third of the arena near the shelter with the conditioned stimulus relative to the total time a subject occupied the two thirds of the arena near either shelter was used as an association index $0 \leq \theta \leq 1$. Indices close to $\theta=1$ indicate that a subject learned to localize access to a shelter based on the position of the magnetic anomaly, whereas indices near $\theta=0.5$ indicate that the association was not learned. Repeated measures analysis of variance (repeated measures ANOVA) was used to compare index means over the 20 tests (Jones \& Kenward, 2015). A one-sample $t$ test was used to compare the mean of $\theta$ for each test to the random expectation of $\theta=0.5$, with a Bonferroni-Holm correction for multiple comparisons, and a two-sample $t$ test was used to compare association indices of subjects conditioned to the magnet or brass stimulus (Glover \& Mitchell, 2016).

\subsubsection{Ethics Statement}

The research was not reviewed by institutional or governmental regulatory authorities, as the experiments involved invertebrates, but we adhered to the ASAB Guidelines for the Use of Animals in Research to minimize unnecessary stress or harm to the animals. The subjects used in our laboratory experiment were captured by hand and transported to Bowling Green State University, where they were maintained under temperature and humidity conditions similar to those in the field. The animals were housed individually, as $P$. laevifrons is largely solitary. The collected subjects were kept for use in additional experiments. 


\section{Results}

\subsection{Field study}

Table 1 summarizes the physical attributes of subjects in the two groups, the order of their displacements, their displacement locations relative to their capture sites, the overall distance they moved after they were displaced, their final direction from their capture site, if they failed to home, and whether they successfully homed. The nightly distances traveled by each subject with respect to its home tree are detailed in Figure 3. No subjects that homed were observed to leave the tree on which they were collected after they returned.

Table 1. Physical attributes of displaced Paraphrynus laevifrons. Displacement distances were approximately $10 \mathrm{~m}$ and occurred on the nights of May 7, 8, and 10, 2016.

\begin{tabular}{cccccccccccc}
\hline ID & Tree & Sex & Size & Trt & DD & DR & DA & FA & LD & FD & Homed \\
\hline T-8405 & A & M & 17.0 & M+ & 7 & 8 & 315 & - & 22.2 & 0 & Y \\
T-8424 & B & F & 19.0 & M+ & 7 & - & 305 & 315 & 8.3 & 7.2 & N \\
T-8444 & C & F & 19.5 & M+ & 7 & 12 & 95 & - & 22.7 & 0 & Y \\
T-8465 & D & M & 18.0 & M+ & 7 & 7 & 220 & - & 10.5 & 0 & Y \\
T-8484 & D & U & 18.5 & M- & 7 & - & 320 & 320 & 9.2 & 6.5 & N \\
T-8505 & E & M & 14.8 & M- & 7 & - & 290 & 173 & 11.6 & 20.8 & N \\
T-8524 & F & F & 16.5 & M+ & 8 & - & 315 & 180 & 10.6 & 13 & N \\
T-8544 & F & F & 16.0 & M- & 8 & - & 345 & 153 & 24.3 & 31 & N \\
T-8564 & G & F & 15.0 & M+ & 10 & - & 350 & 90 & 26.6 & 14 & N \\
T-8583 & H & U & 17.0 & M+ & 10 & 11 & 265 & - & 9.6 & 0 & Y \\
T-8604 & I & F & 18.0 & M+ & 10 & - & 70 & 88 & 25.3 & 12 & N \\
T-8624 & I & M & 18.5 & M- & 10 & 12 & 80 & - & 21.5 & 0 & Y \\
\hline
\end{tabular}

Note: ID, Transmitter number; Tree, tree from which individual was captured, arbitrarily labeled A-I; Sex: male, M, female, F, or uncertain, U; Size, prosoma width, mm; Trt, fitted with magnet, $\mathrm{M}+$, or a brass disk, $\mathrm{M}-$; $\mathrm{DD}$, date of displacement; DR, night that a subject returned, if a subject homed; DA, direction of home tree $(\mathrm{H})$ from release site relative to north, degrees; FA, direction of last observed location from $\mathrm{H}$ for subjects that failed to home, with the direction of $\mathrm{H}$ from the release site standardized to $360^{\circ}$, degrees; $\mathrm{LD}$, the total linear distance a subject traveled post-displacement, m; FD, distance of a subject from its collection site on May 15, 2016, the last day on which positional information was collected, m; Homed, returned to capture site, Y, or failed to return by May 15, N. 

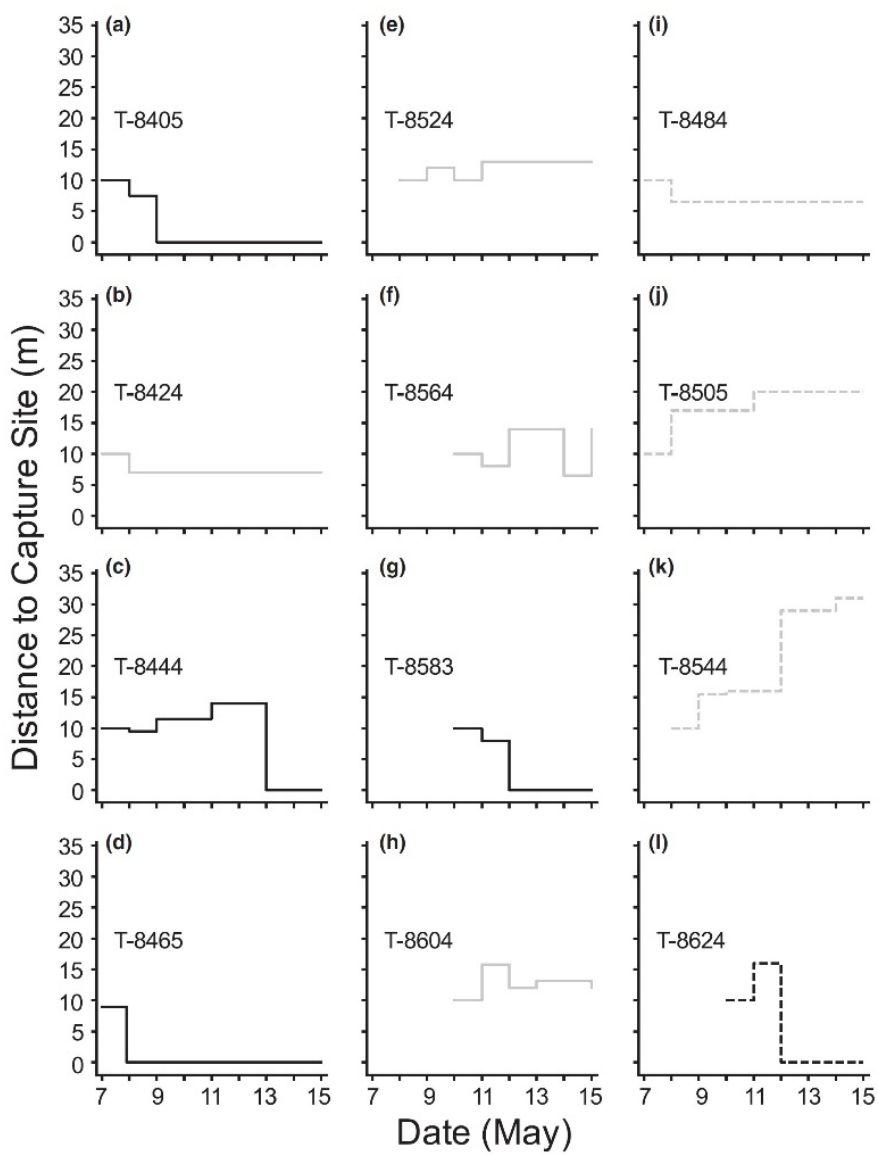

Figure 3. Distance of Paraphrynus laevifrons to their home tree for subjects fitted with a (a$\mathrm{h}$, solid lines) magnet or (i-l, dashed lines) brass disk. The distances for subjects that homed (black lines) or failed to home (gray lines) are plotted for each day after a subject was displaced, where the first point for all subjects is the displacement distance, $10 \mathrm{~m}$. Transmitter numbers correspond to Table 1.

A total of five subjects homed, one on the night it was displaced. Displacement directions between subjects that homed and subjects that failed to home and did not differ (Table 1, DA: $\left.U^{2}=0.147, p>.1\right)$. The displacement directions of subjects in the $\mathrm{M}+$ and $\mathrm{M}-$ groups also did not differ $\left(U^{2}=0.119, p>.1\right)$. The eight subjects fitted with a magnet moved in a homeward direction on the night they were displaced, whereas the four subjects in the control group, fitted with brass, appear to have moved in a random direction from their release site (Figure 4). Four of the eight subjects in the $\mathrm{M}+$ group homed successfully, and one of the four subjects in the $\mathrm{M}-$ group homed. These return rates do not differ significantly (Fisher exact test, $p=.5758$ ). The return rate of subjects fitted with a magnet was also similar that of control subjects or vision-deprived subjects in an earlier study-likewise displaced $10 \mathrm{~m}$ - fitted only with a radio transmitter, where four of six and six of 10 individuals homed, respectively (Fisher exact tests, $p=.6084, p=1$; Bingman et al., 2017). Thus, 
the magnets appear not to have negatively impacted the ability of an individual to locate the tree from which it was displaced.
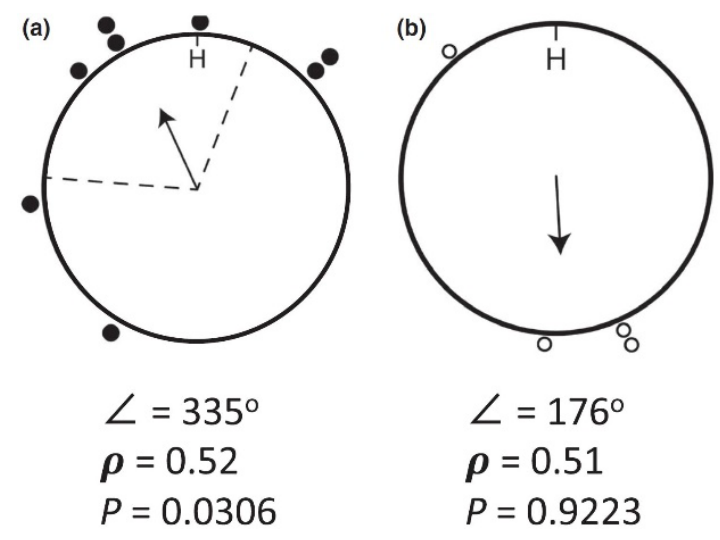

Figure 4. Directional movement of subjects from their respective release sites after $10 \mathrm{~m}$ displacements. The orientation on the morning after displacement is shown for subjects (a) fitted with a magnet or (b) brass disk, where the home tree direction $\mathrm{H}$ is normalized to $360^{\circ}$. The arrows indicate the mean orientation vector. The length of the vector is $0 \leq \rho$ $\leq 1$, where an alignment of all subjects in the same direction corresponds to $\rho=1$. $V$ test probabilities are indicated. The magnet-fitted subjects were significantly oriented, and the 95 percent confidence interval (wedge) of the vector direction includes the homeward direction, $\mathrm{H}$.

Positional data collected on May 15, the last day on which the location of subjects was recorded, reveal that the seven individuals that failed to home were not generally oriented on a homeward trajectory (Table 1, FA: $V$ test, $\rho=0.26, p=.7638$ ). The orientation of these subjects did not differ between the $\mathrm{M}+$ and $\mathrm{M}-$ groups $\left(U^{2}=0.095, p>.1\right)$. Five of these subjects were farther than $10 \mathrm{~m}$ to their shelter and, hence, had made no homeward progress in the five to eight nights after they were displaced, and two of the three subjects in the M- group that had not homed were located more than twice the 10-m displacement distance from their respective capture sites (Table 1; Figure 3). Three of the seven subjects that had not homed were active on the night of May 14 and could potentially have returned to their respective home trees after our observations ended. Two of these subjects (T-8564, T-8604) were fitted with a magnet, and one (T-8544) was fitted with a brass disk (Figure 3). Thus, the conclusion that the magnets had no discernable negative impact on the ability of subjects to home would not likely have changed if our observations had not been truncated.

\subsection{Laboratory study}

Results of the laboratory experiment reveal that subjects failed to learn the conditioned association between the magnetic landmark and access to a shelter. The overall mean association index for $\mathrm{M}+$ subjects conditioned to the magnetic anomaly was $\bar{\Theta} \pm S E=0.54 \pm$ 0.03 . This mean is nearly identical to the index mean of $0.51 \pm 0.03$ for the $\mathrm{M}$ - subjects 
conditioned to avoid the magnetic landmark and, hence, data were pooled ( $t_{4}=0.79, p=$ .4704 ). Index means did not vary over the 20 test trials (Figure $5 ; F_{19}, 85.81=1.59, p=.785$ ). Indeed, the mean association index did not differ from the random expectation of $\theta=0.5$ in any of the 20 test trials, not even after 50 training trials over 10 daily sessions. Thus, neither the geomagnetic intensity - particularly with regard to the $x$ field component-nor the horizontal polarity of the field appears to have cued the location of the accessible shelter.

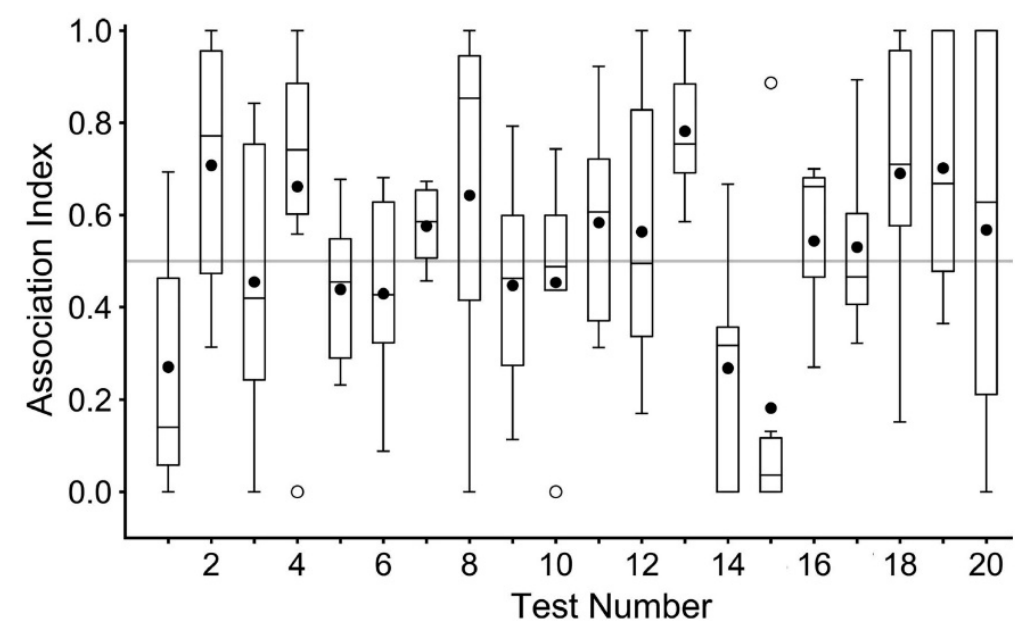

Figure 5. Box plots of association indices $0 \leq \theta \leq 1$ in the 20 tests. Boxes show the interquartile range IQR, median (horizontal line in IQR boxes), and lowest and highest values (whiskers) within 1.5 IQR of the upper and lower quartiles. Index means (solid dots) and prospective outliers (open circles) for each test are also plotted. No association index mean differs significantly from the random expectation of $\theta=0.5$ after a Bonferroni-Holm correction for multiple comparisons.

\section{Discussion}

The results of the field experiment suggest that navigation by displaced Paraphrynus laevifrons is not impeded by a local disruption of the ambient magnetic field. The initial movement of subjects fitted with a magnet was toward the tree from which they were captured, and they were as likely to return to their respective home trees as subjects fitted with a brass disk. Indeed, the home-oriented movement and rate of return we observed for subjects fitted with a magnet are similar to those of control subjects or vision-deprived subjects in an earlier study - likewise displaced $10 \mathrm{~m}$ - fitted only with a radio transmitter, where four of six and six of 10 individuals homed, respectively (Bingman et al., 2017). In our laboratory experiment, $P$. laevifrons also failed to associate a magnetic landmark with access to a shelter. The amblypygid Phrynus marginemaculatus, in contrast, readily solves the same problem in 1-14 trials in two daily sessions when an olfactory cue serves as the conditioned stimulus, and the learned association is retained for at least 2 weeks 
(Wiegmann et al., 2019). In this study, P. laevifrons failed to learn the magnet-shelter contingency in 50 trials conducted over 10 daily sessions.

There are several potential explanations for the observed lack of influence of the magnets on P. laevifrons behavior. Perhaps P. laevifrons have no transduction mechanism for detection of the magnetic field. Indeed, we know of no study in which geomagnetic field sensitivity is documented in any arachnid. This explanation seems doubtful, however, given the near-ubiquitous sensitivity of other arthropods to the polarity of the magnetic field (reviewed by Riveros \& Srygley, 2010; Wajnberg et al., 2010; Wajnberg, Cernicchiaro, \& Esquivel, 2004). Perhaps subjects in our field experiment were insensitive to the magnetic treatment because the sensory tissue for transduction is located on the distal articles of the antenniform legs, which when outstretched span $24-27 \mathrm{~mm}$, well beyond the magnetic field created around the prosoma by the magnet (Figure 1; Weygoldt, 2000). Indeed, the locus of magnetic sensitivity appears to be in the antennae of leaf cutter ants (Wajnberg et al., 2010; Alves et al., 2014; see also Oliveira et al., 2010; Wajnberg, Rossi, \& Esquivel, 2017). Results of our laboratory experiment suggest, however, that this explanation, too, is unlikely. The entire body of a subject, antenniform legs included, necessarily passed through the induced magnetic anomaly when the magnet-cued shelter was approached and, still, the association between the magnetic landmark and access (or lack of access) to a shelter was not learned. Failure to learn the association might also be explained if the magnets positioned outside the arena effectively saturated the magnetic sense mechanism (Riveros et al., 2010; Srygley et al., 2006). The magnets we used in our laboratory experiment, however, were relatively weak in comparison to magnets used in suppression studies and generated an intensity anomaly similar to or somewhat weaker than those in experiments that revealed a magnetic sense in bees or ants (Walker \& Bitterman, 1989; Kirschvink \& Kobayashi Kirshvink, 1991; Buehlmann et al., 2012).

The most parsimonious explanation for the combined results of our experiments would seem to be that the geomagnetic field does not provide essential spatial information as $P$. laevifrons navigates the rainforest floor and, hence, that the geomagnetic field is ignored in the context of navigation or, perhaps, even undetected. Magnetic effects on animal orientation are, however, often not easily elicited, and alternative experimental conditions may yet uncover some geomagnetic influence on amblypygid spatial behavior. In any case, positional information derived from the ambient magnetic field does not appear to be necessary for $P$. laevifrons to navigate successfully, just as information derived from visual cues seems to be inessential (Bingman et al., 2017; Hebets, Aceves-Aparicio, et al., 2014). Navigation by amblypygids is nearly completely impeded, in contrast, by the disruption of inputs from sensilla on their antenniform legs, and hence, it seems that progress toward a mechanistic characterization of their navigation behavior would profitably benefit if the multimodal sensory inputs to these appendages can be somehow disentangled.

Acknowledgments - This project was supported by National Geographic Society award 9400-13 to V.P.B., D.D.W., and E.A.H. and by National Science Foundation award IOS 1457304 to V.P.B. and D.D.W. Three anonymous reviewers and our colleague L. Fulcher provided helpful comments.

Conflict of Interest - The authors have no conflicting interests. 


\section{References}

Alves, O. C., Srygley, R. B., Riveros, A. J., Barbosa, M. A., Esquivel, D. M. S., \& Wajnberg, E. (2014). Magnetic anisotropy and organization of nanoparticles in heads and antennae of neotropical leafcutter ants, Atta colombica. Journal of Physics D: Applied Physics, 47, 435401.

Batschelet, E. (1981). Circular statistics in biology. New York, NY: Academic Press.

Beck, L., Foelix, R., Gödeke, E., \& Kaiser, R. (1977). Morphologie, Larvalentwicklung und Haarsensillen des Tastbeinpaares der Geißelspinne Heterophrynus longicornis butler (Arach., Amblypygi). Zoomorphologie, 88, 259-276. (10.1007/bf009 95476)

Beck, L., \& Görke, K. (1974). Tagesperiodik, Revierverhalten und Beutefang der Geissselspinne Admetur pumilio C. L. Koch Im Freiland. Zeitschrift Für Tierpsychologie, 35, 173-186. (10.1111/j.14390310.1974.tb00442.x)

Bingman, V. P., Graving, J. M., Hebets, E. A., \& Wiegmann, D. D. (2017). Importance of the antenniform legs, but not vision, for homing by the neotropical whip spider Paraphrynus laevifrons. Journal of Experimental Biology, 220, 885-890. https://doi.org/10.1242/jeb.149823

Buehlmann, C., Hansson, B. S., \& Knaden, M. (2012). Desert ants learn vibration and magnetic landmarks. PLoS One, 7(3), e33117. (10.1371/ journ al.pone.00331 17)

Cardé, R. T. (2008). Insect migration: Do migrant moths know where they are heading? Current Biology, 18, R472-R474. https://doi.org/10.1016/j.cub.2008.04.018

Casto, P., Gosser, J., Wiegmann, D. D., Hebets, E. A., \& Bingman, V. P. (2019). Self-derived chemical cues support home refuge recognition in the whip spider Phrynus marginemaculatus (Amblypygi: Phrynidae). The Journal of Arachnology, 47, 290-292. https://doi.org/10.1636/JoA-S-18-067

Chapman, J. W., Reynolds, D. R., Hill, J. K., Sivell, D., Smith, A. D., \& Woiwod, I. P. (2008). A seasonal switch in compass orientation in a high-flying migrant moth. Current Biology, 18, R908-R909.

Cheng, K. (2012). Arthropod navigation: Ants, bees, crabs, spiders finding their way. In T. R. Zentall, \& E. A. Wasserman (Eds.), The Oxford Handbook of Comparative Cognition (pp. 347-365). New York, NY: Oxford University Press.

Chittka, L., Williams, N. M., Rasmussen, H., \& Thomson, J. D. (1999). Navigation without vision: Bumblebee orientation in complete darkness. Proceedings of the Royal Society of London, Series B: Biological Sciences, 266, 45-50. https://doi.org/10.1098/rspb.1999.0602

Collett, M., \& Collett, T. S. (2017). Path integration: Combining optic flow with compass orientation. Current Biology, 27, R1108-R1129. https://doi.org/10.1016/j.cub.2017.09.004

Dommer, D. H., Gazzolo, P. J., Painter, M. S., \& Phillips, J. B. (2008). Magnetic compass orientation by larval Drosophila melanogaster. Journal of Insect Physiology, 54, 719-726.

Foelix, R. F. (1975). Occurrence of synapses in peripheral sensory nerves of arachnids. Nature, 254, 146-148. https://doi.org/10.1038/254146a0

Foelix, R., \& Hebets, E. (2001). Sensory biology of whip spiders (Arachnida, Amblypygi). Andrias, 15, 129-140.

Frier, H. J., Edwards, E., Smith, C., Neale, S., \& Collet, T. S. (1996). Magnetic compass cues and visual pattern learning in honeybees. Journal of Experimental Biology, 199, 1353-1361.

Glover, T., \& Mitchell, K. (2016). An Introduction to Biostatistics (3rd ed). Long Grove, IL: Waveland Press Inc.

Hebets, E. A. (2002). Relating the unique sensory system of amblypygids to the ecology and behavior of Phrynus parvulus from Costa Rica (Arachnida, Amblypygi). Canadian Journal of Zoology, 80, 286295. https://doi.org/10.1139/z02-006 
Hebets, E. A., Aceves-Aparicio, A., Aguilar-Argüello, S., Bingman, V. P., Escalante, I., Gering, E. J., . . . Stafstrom, J. A. (2014). Multimodal sensory reliance in the nocturnal homing of the amblypygid Phrynus pseudoparvulus (Class Arachnida, order Amblypygi). Behavioural Processes, 108, 123-130. https://doi.org/10.1016/j.beproc.2014.09.014

Hebets, E. A., Gering, E. J., Bingman, V. P., \& Wiegmann, D. D. (2014). Nocturnal homing in the tropical amblypygid Phrynus pseudoparvulus (class Arachnida, order Amblypygi). Animal Cognition, 17, 1013-1018. https://doi.org/10.1007/s10071-013-0718-8

Heinze, S., Narendra, A., \& Cheung, A. (2018). Principles of insect path integration. Current Biology, 28, R1043-R1058.

Jones, B., \& Kenward, M. G. (2015). Design and analysis of cross-over trials, (3rd ed). Boca Raton, FL: CRC Press.

Kirschvink, J., \& Kobayashi Kirschvink, A. (1991). Is geomagnetic sensitivity real? Replication of the Walker-Bitterman magnetic conditioning experiment in honey bees. American Zoologist 31, 169-183.

Layne, J. E., Barnes, W. J. P., \& Duncan, L. M. (2003a). Mechanisms of homing in the fiddler crab Uca rapax 1 . Spatial and temporal characteristics of a system of small-scale navigation. Journal of Experimental Biology, 206, 4413-4423. (10.1242/jeb.00660)

Layne, J. E., Barnes, W. J. P., \& Duncan, L. M. (2003b). Mechanisms of homing in the fiddler crab Uca rapax 2. Information sources and frame of reference for a path integration system. Journal of Experimental Biology, 206, 4425-4442. (10.1242/jeb.00661)

Mardia, K. V., \& Jupp, P. E. (2000). Directional statistics. New York, NY: John Wiley \& Sons Ltd.

Mittelstaedt, H., \& Mittelstaedt, M. L. (1982). Homing by path integration. In F. Papi, \& H. G. Walraff (Eds.), Avian Navigation (pp. 290-297). New York, NY: Springer-Verlag.

Nørgaard, T., Gagnon, Y. L., \& Warrant, E. J. (2012). Nocturnal homing: Learning walks in a wandering spider? PLoS One, 7, e49263. https://doi.org/10.1371/journal.pone.0049263

Nørgaard, T., Nilsson, D. E., Henschel, J. R., Garm, A., \& Wehner, R. (2008). Vision in the nocturnal wandering spider Leucorchestris arenicola (Araneae: Sparassidae). Journal of Experimental Biology, 211, 816-823.

Oliveira, J. F., Wajnberg, E., Esquivel, D. M. S., Weinkauf, S., Winklhofer, M., \& Hanzlik, M. (2010). Ant antennae: Are they sites for magnetoreception? Journal of the Royal Society Interface, 7, 143152. https://doi.org/10.1098/rsif.2009.0102

Ortega-Escobar, J. (2002). Evidence that the wolf-spider Lycosa tarentula (Araneae, Lycosidae) needs visual input for path integration. Journal of Arachnology, 30, 481-486.

Ortega-Escobar, J., \& Ruiz, M. A. (2014). Visual odometry in the wolf spider Lycosa tarantula (Araneae: Lycosidae). Journal of Experimental Biology, 217, 395-401. https://doi.org/10.1242/jeb.091868

Ortega-Escobar, J., \& Ruiz, M. A. (2017). Role of the different eyes in the visual odometry in the wolf spider Lycosa tarantula (Araneae, Lycosidae). Journal of Experimental Biology, 220, 259-265. https:// doi.org/10.1242/jeb.145763

Perry, C. J., Barron, A. B., \& Cheng, K. (2013). Invertebrate learning and cognition: Relating phenomena to neural substrate. Wiley Interdisciplinary Reviews: Cognitive Science, 4, 561-582. (10.1002/wcs.1248)

Reyes-Alcubilla, C., Ruiz, M. A., \& Ortega-Escobar, J. (2009). Homing in the wolf spider Lycosa tarantula (Araneae, Lycosidae): The role of active locomotion and visual landmarks. Naturwissenshaften, 96, 485-494. https://doi.org/10.1007/s00114-008-0498-1

Riveros, A. J., \& Srygley, R. B. (2008). Do leafcutter ants, Atta colombica, orient their path-integrated home vector with a magnetic compass? Animal Behavior, 75, 1273-1281. https://doi.org/10.1016/ j.anbehav.2007.09.030 
Riveros, A. J., \& Srygley, R. B. (2010). Migration, orientation and navigation: Magnetic compasses in insects. In M. D. Breed, \& J. Moore (Eds.), Encyclopedia of animal behavior, Vol. 2 (pp. 305-313). Oxford, UK: Academic Press.

Santer, R. D., \& Hebets, E. A. (2009). Tactile learning by a whip spider, Phrynus marginemaculatus C. L. Koch (Arachnida, Amblypygi). Journal of Comparative Physiology A, 195, 393-399. https://doi.org/ 10.1007/s00359-009-0417-8

Santer, R. D., \& Hebets, E. A. (2011). The sensory and behavioural biology of whip spiders (Arachnida, Amblypygi). In S. J. Simpson, \& J. Casas (Eds.), Advances in Insect Physiology (Vol. 41), (pp. 1-64). Burlington, MA: Academic Press.

Segovia, J. M. G., Neco, L. C., \& Willemart, R. H. (2018). On the habitat use of the Neotropical whip spider Charinus asturius (Arachnida: Amblypygi). Zoologia, 35, e12874. (10.3897/zoologia.35.e12874)

Sokal, R. R., \& Rohlf, F. J. (2012). Biometry: Principles and practice of statistics in biological research, 4 th ed. New York, NY: W. H. Freeman and Company.

Srygley, R. B., Dudley, R., Oliveira, E. G., \& Riveros, A. J. (2006). Experimental evidence for a magnetic sense in Neotropical migrating butterflies (Lepidoptera: Pieridae). Animal Behavior, 71, 183191. https://doi.org/10.1016/j.anbehav.2005.04.013

Steck, K., Hansson, B. S., \& Knaden, M. (2009). Smells like home: Desert ants, Cataglyphis fortis, use olfactory landmarks to pinpoint the nest. Frontiers in Zoology, 6, 5. (10.1186/1742-9994-6-5)

Steck, K., Hansson, B. S., \& Knaden, M. (2011). Desert ants benefit from combining visual and olfactory landmarks. Journal of Experimental Biology, 214, 1307-1312. https://doi.org/10.1242/jeb.053579

Strausfeld, N. J. (2012). Arthropod brains: Evolution, functional elegance and historical significance. Cambridge, MA: Harvard University Press.

Vácha, M., Drštková, D., \& Půžová, T. (2008). Tenebrio beetles use magnetic inclination compass. Naturwissenschaften, 95, 761-765.

Wajnberg, E., Acosta-Avalos, D., Alves, O. C., de Oliveira, J. F., Srygley, R. B., \& Esquivel, D. M. S. (2010). Magnetoreception in eusocial insects: An update. Journal of the Royal Society Interface, 7, S207-S225.

Wajnberg, E., Cernicchiaro, G. R., \& Esquivel, D. M. S. (2004). Antennae: The strongest magnetic part of the migratory ant. BioMetals, 17, 467-470. https://doi.org/10.1023/B:BIOM.0000029443.93732.62

Wajnberg, E., Rossi, A. L., \& Esquivel, D. M. S. (2017). Titanium and iron titanium oxide nanoparticles in antennae of the migratory ant Pachycondyla marginata: An alternative magnetic sensor for magnetoreception? BioMetals, 30, 541-548. https://doi.org/10.1023/B:BIOM.0000029443.93732.62

Walker, M. M. (1997). Magnetic orientation and the magnetic sense in arthropods. In M. Lehrer (Eds.), Orientation and communication in arthropods. EXS: Vol 84, (pp. 187-213). Basel, Switzerland: Birkhäuser.

Walker, M. M., \& Bitterman, M. E. (1989). Attached magnets impair magnetic field discrimination by honeybees. Journal of Experimental Biology, 141, 447-451.

Warrant, E., \& Dacke, M. (2010). Visual orientation and navigation in nocturnal arthropods. Brain, Behavior and Evolution, 75, 156-173. (10.1159/000314277)

Wehner, R. (2003). Desert ant navigation: How miniature brains solve complex tasks. Journal of Comparative Physiology. A, Neuroethology, Sensory, Neural, and Behavioral Physiology, 189, 579-588. (10.1007/s00359-003-0431-1)

Weygoldt, P. (2000). Whip spiders (Chelicerata: Amblypygi): Their Biology, Morphology and Systematics. Stenstrup, Denmark: Apollo Books. 
Wiegmann, D. D., Hebets, E. A., Gronenberg, W., Graving, J. M., \& Bingman, V. P. (2016). Amblypygids: Model organisms for the study of arthropod navigation mechanisms in complex environments? Frontiers in Behavioural Neurosciences, 10, 47.

Wiegmann, D. D., Moore, C. H., Flesher, N. R., Harper, E. D., Keto, K. R., Hebets, E. A., \& Bingman, V. P. (2019). Nocturnal navigation by whip spiders: Antenniform legs mediate neat-distance olfactory localization of a shelter. Animal Behavior, 149, 45-54. 